Acta Hispanica (2015) 20: 143-144

\title{
VIVIR EN EL MUNDO DE LAS TRADUCCIONES
}

\section{SANDA-VALERIA MORARU}

\author{
Universidad Babeş-Bolyai
}

Estudios de traducción y lenguajes de especialidad Cluj-Napoca, Editorial Risoprint, 2014, 210 p.

La autora del libro, Olivia Petrescu, es una conocida hispanista, docente en el Departamento de Lenguas Modernas Aplicadas de la Facultad de Letras de la Universidad "Babeş-Bolyai" de Cluj-Napoca (Rumanía). Olivia Petrescu es doblemente graduada en Filología Inglesa-Filología Hispánica y Derecho y es también doctora en Literatura comparada por la misma universidad. En la misma facultad imparte, entre otras, asignaturas como Estudios culturales y Traducciones especializadas.

Debido a su doble graduación, los intereses de la autora se circunscriben, por un lado, en el área de la literatura y la cultura hispánicas, y, por otro lado, en el dominio tan amplio y dinámico de la traducción especializada.

El libro abre con un Prólogo (p. 9-12), escrito por la profesora fundadora de los estudios de traducción en la Facultad de Letras de Cluj-Napoca, la señora Rodica Baconsky; continúa con una Introducción (p. 13-18), escrita por la autora.

El volumen se divide en dos partes: la primera, tiene como tema principal la traducción especializada, mientras que la segunda se centra en la traducción literaria. De este modo, Olivia Petrescu compagina sus intereses investigadores y los refleja en los estudios incluidos en esta obra.

En la primera parte se distinguen los siguientes capítulos: Metodología y técnicas actuales de la traducción especializada (p. 21-42); El papel de los latinismos en la terminología jurídica (p. 43-52); Aspectos de la neología en el lenguaje jurídico. Marco europeo y especificidades rumanas, españolas y catalanas (p. 53-69); Herramientas del portal de la Unión Europea utilizadas para la traducción de sentencias jurídicas (p. 70 84); Dificultades lingüísticas y culturales en la traducción jurídica (p. 85-100); En torno a la argumentación y a las estrategias discursivas y de traducción (p. 101-114) y Estrategias actuales de comunicación profesional multilingüe y especializada y su uso en la inserción laboral (p. 115-135).

La segunda parte pone de manifiesto las dificultades y los retos que suponen la traducción literatura, a la que Olivia Petrescu también se dedica, y representa el reflejo de su experiencia como traductora de uno de los libros de la literatura mexicana contemporánea, Un dulce olor a muerte (1994) de Guillermo Ariaga, que tradujo al rumano bajo el título Un dulce miros de moarte, Bucureşti, Editorial Vellant, 2008. El análisis tiene 
como punto de partida las técnicas utilizadas en el proceso de traducción del libro y pone de relieve los desafíos de la traductora a la hora de traducir algunos de los elementos específicos de la cultura mexicana que casi no tienen equivalente en rumano.

Los tres capítulos que integran la segunda parte del libro son los siguientes: Cultura y Literatura en la traducción. Los culturemas mexicanos (p. 139-164); Borges en el espejo de las traducciones. Una perspectiva rumana (p. 165-182) y Arte contemporáneo y lenguajes de especialidad (p. 182-196). No podían faltar las Conclusiones (p. 197-198) y una amplia bibliografía (p. 199-210), consultada por la autora.

El contenido de cada capítulo se basa en la bibliografía ya existente en el dominio de la traductología, que se aplica a casos prácticos, concretos de traducción, con ejemplos muy bien elegidos y con posibles variantes o propuestas de traducción de términos que les plantean problemas no solamente a los alumnos que se inician en el estudio de la traducción jurídica o de cualquier otro tipo, sino también a los traductores profesionales. El hecho de que Olivia Petrescu se haya graduado en Derecho hace que sus propuestas de traducción se consideren como totalmente válidas y pertinentes, porque toda su experiencia en esta área se manifiesta en la traducción de dichos términos.

Con una lectura amena, el libro escrito y publicado por Olivia Petrescu es una obra valiosa y un recurso bibliográfico muy útil tanto para los estudiantes de Traducción y Filología, como también para todos los que estén interesados en los temas investigados a lo largo de sus estudios que forman parte de esta obra. 


\section{AUTORES DE ESTE VOLUMEN}

BOUBA KIDAKOU, ANTOINE es licenciado en letras hispánicas por la Universidad de Yaundé (Camerún). Es doctor en filología hispánica por la UNED (Madrid, España). Actualmente es profesor titular de literatura española e hispanoafricana en la Escuela Normal Superior de la Universidad de Maroua,. Es subdirector de asuntos académicos, de investigación y de cooperación en dicho centro y coordinador del equipo de redacción de la revista Kaliao. Lleva sus investigaciones sobre la literatura española, la literatura de viajes y la literatura africana escrita en lengua española.

GUTIÉRREZ GÓMEZ VELASCO, DOLORES es licenciada en relaciones internacionales. Es doctora en literatura por el Centro de Investigación y Docencia en Humanidades del Estado de Morelos. Obtuvo su grado con la tesis Transformación de la identidad de los personajes femeninos en la cuentística de Rosario Castellanos e Inés Arredondo. Está dedicada a la docencia e imparte talleres de creación literaria.

BRAN, RĂZVAN es licenciado en filología hispánica, griega y clásica. Es doctor en lingüística por la Universidad de Bucarest e hizo su doctorado en lexicología y terminología. Es profesor asistente del Departamento de Lingüística Románica, Lenguas y Literaturas Iberorrománicas e Italiano de la Universidad de Bucarest, donde imparte cursos prácticos de ELE y seminarios de fonética, morfología y sintaxis. Sus investigaciones se centran en la sintaxis, la didáctica de ELE y la lexicología.

GUTIÉRREZ MUÑOZ, ÓSCAR es licenciado en educación, bachiller en humanidades y profesor de español. Es magíster en literaturas hispánicas (Universidad de Concepción, Chile). Es colaborador en el Proyecto FONDECYT No 11121221: Apuntes sobre la dimensión museal de la literatura latinoamericana o los museos de papel. En 2015 fue ganador del concurso FONDART (Fondo nacional de la cultura y las artes. Chile), por su proyecto Lineas de Fuga. En 2016 publica la novela gráfica Lineas de Fuga, en colaboración con el ilustrador Cristián Toro.

KATONA, ESZTER es doctora en historia por la Universidad de Szeged, profesora asociada del Departamento de Estudios Hispánicos en la misma Universidad. Sus investigaciones y publicaciones se centran en el ámbito de la historia de España, la literatura española y la recepción húngara de la literatura española con especial atención a la recepción de la obra de Federico García Lorca. 
KROLL, SIMON se ha doctorado por la Universidad de Viena con una tesis doctoral sobre los autógrafos de Pedro Calderón de la Barca y su proceso de escritura. Colabora en el proyecto de investigación Secrets and Secrecy in Calderón's Comedies and in Spanish Golden Age Culture, dirigido por Wolfram Aichinger. Sus investigaciones se centran en la literatura hispánica de los Siglos de Oro con un segundo enfoque en la narrativa hispánica y francesa del siglo XX.

MANKKOWSKA, JOANNA es licenciada en filología francesa. Es doctora en Letras por la Universidad de Varsovia. Hizo su doctorado sobre el ritual y la ceremonia en la práctica dramática del Teatro del Absurdo español y francés. Es profesora encargada de cursos de literatura y de cultura de España en la Universidad de Ciencias Sociales y Humanidades (SWPS) de Varsovia (Polonia). Sus investigaciones se centran en la dramaturgia del Nuevo Teatro español, el mito de Don Juan y el del caballero andante, los ritos y ceremonias en el teatro.

PARRA SÁNCHEZ, DIEGO ERNESTO es licenciado en filología hispánica por la Universidad de Salamanca y cuenta con un máster en literatura española e hispanoamericana. En la actualidad trabaja como personal docente e investigador en la Universidad del País Vasco y cursa sus estudios de doctorado con una tesis sobre nuevas narrativas policíacas en América Latina. Sus investigaciones se centran en la narrativa hispánica del siglo XX y en las relaciones interdisciplinares entre literatura y otras artes como cine o pintura. Ha colaborado también con revistas como Miríada Hispánica o Cultura, Lenguaje y Representación.

MORARU, SANDA-VALERIA es licenciada en filología hispánica y filología inglesa. Cursó estudios de máster en Estudios Europeos Comparados. Es doctora en filología por la Universidad “1 Decembrie 1918” de Alba Iulia (Rumanía). Hizo su doctorado sobre la obra de George Uscătescu, uno de los intelectuales rumanos exiliados en España durante la dictadura comunista de Ceauşescu. Es lectora titular y coordinadora de la Cátedra de filología hispánica del Departamento de Lenguas y Literaturas Romances de la Universidad Babeş-Bolyai de Cluj-Napoca (Rumanía). Sus investigaciones se centran en las relaciones culturales entre Rumanía, España y América Latina, la traductología y la didáctica del español como lengua extranjera.

PETRESCU, OLIVIA N. es doctora magna cum laude en literatura Ccmparada y doblemente graduada por la Universidad "Babeş-Bolyai" de Cluj-Napoca en Letras y Derecho, profesora titular en el Departamento de Lenguas Modernas Aplicadas de la Facultad de Letras de la misma universidad. En calidad de docente, editora, evaluadora, coordinadora de tesis, trabajos finales y proyectos culturales, a la vez que traductora e intérprete jurada, sus intereses profesionales y áreas de investigación son la traducción especializada y los estudios culturales. 
ROBERTO RODRÍGUEZ, MILÁN es licenciado y posgraduado en historia por la Universidad de Barcelona. Es doctor en filología por la Universidad de Atenas. Hizo su doctorado sobre el ensayismo español contemporáneo. Es profesor contratado del Departamento de Humanidades de la Hellenic Open University. Sus investigaciones se centran en el ensayismo de reflexión nacional y en la novela popular en España.

SZILÁGYI CHEBI, MARÍA ELENA es licenciada en Viola y Música de Cámara por la Universidad de Debrecen (2007). Es traductora literaria, egresada del Instituto Balassi de Budapest (2010). Tiene un grado en filología hispánica y especialización catalana en la Universidad de Szeged (2014) y actualmente es alumna del último curso del máster de E/LE en dicha universidad. Trabaja como profesora de lengua y civilización española en el Instituto bilingüe Vetési Albert de Veszprém, Hungría. 